\title{
Study of The Biological Parameters, According to Generation, of Bruchidius Atrolineatus (Coleoptera-Bruchina), A Major Pest of Cowpea (Vigna Unguiculata Walp.) in the Sahelian Zone. Moumouni DA*
}

Faculty of Agronomic Sciences, University of Tahoua, Niger

DOI: $10.36347 / \mathrm{sajb} .2020 . v 08 i 08.002$

| Received: 17.07.2020 | Accepted: 25.07.2020 | Published: 08.08.2020

*Corresponding author: Adamou Moumouni Dan Mairo

\section{Abstract}

In the Sahelian zone, Bruchidius atrolineatus (Coleoptera-Bruchidae) is one of the major pests of cowpea seeds (Vigna unguiculata (L.) Walp). The objective is to study the biological parameters of this insect in the Sahelo-Sudanian zone of Niger. The objective is to study the biological parameters of this insect in the Sahelo-Sudanian zone of Niger. To make strains from this area were collected and the biological parameters of $B$. atrolineatus were studied according to the generations. Analysis of our results shows that second generation insects live longer than first generation insects. The results obtained on fertility show that the latter is low whatever the generation considered, but also with a very low larval survival rate and an emergence rate. Analysis of our results shows that second generation insects live longer than first generation insects. The results obtained on fertility show that the latter is low whatever the generation considered, but also with a very low larval survival rate and an emergence rate. The evolution of mortality shows that it is much more spread out in time for the second generation than for that of the first generation. Taking gender into account, our results show that females die faster than males, regardless of generation. The evolution of fertility shows that most of the eggs are laid during the first four to five days of the infestation, whatever the generation. These data are essential for mastering the bioecology of B. atrolineatus in order to propose effective control methods.

Keywords: Vigna unguiculata, Bruchidius atrolineatus, biological parameters, Sahelo-Sudanian zone, Niger.

Copyright @ 2020: This is an open-access article distributed under the terms of the Creative Commons Attribution license which permits unrestricted use, distribution, and reproduction in any medium for non-commercial use (NonCommercial, or CC-BY-NC) provided the original author and source are credited

\section{INTRODUCTION}

Cowpea, Vigna unguiculata Walp. is cultivated all over the world with a total production which was not far from 4 million tonnes in 2002. In Niger, cowpea production is estimated at 1, 972, 826 tonnes in 2010 compared to 787,472 tonnes in 2009 and 1, 543, 943 tonnes in 2008 [1]. Often consumed by populations in both towns and villages, cowpeas, rich in protein, help to compensate for food deficits. It enriches the soil with its nitrogen and has become a cash crop with an external market that works well between Nigeria and most of the West African countries. Among other causes unfavorable to its culture, insects, diseases and parasitic plants prevent it from developing properly. However, cowpea production is affected by climatic vagaries and limited by losses caused by attacks from a rich and varied entomofauna at all stages of its development [2]. After harvesting, conservation of cowpeas is made difficult by Bruchidae beetles, the recognized most devastating species of which are Bruchidius atrolineatus Pic. and Callosobruchus maculatus Fab. which appear in crops at the end of the rainy season and breed there during the cowpea fruiting period. To effectively fight this cowpea insect in Africa, it is necessary to have a thorough knowledge of its biology. Thus it has been recognized for many years, according to Ayres and Lombardero [3], even modest climatic changes are likely to have an impact on the abundance and distribution of insect pests. The work carried out by Lale \& Vidal [4], made it possible to show that the variability observed in the fertility of Callosobruchus subinnotatus compared to the data in the literature would be linked to climatic conditions and to the photoperiod of the environment which influences the oviposition of females and larvae development with optimum egg laying and development observed at $30^{\circ} \mathrm{C}$. This variability is also linked to the strain used, as observed in C. maculatus [5-7]. By studying the demographic parameters of $C$. maculatus under natural conditions in Burkina Faso, Sanon [8] has shown that the increase in temperature and relative humidity in this species leads to an increase in the intrinsic capacity for growth and a decrease in generation time. According to this author, the fertility and the duration of development of this species of 
Callosobruchus vary according to the generations. The present study follows this same logic and aims to know the variations of the biological parameters of $B$. atrolineatus according to the generations in Niger.

\section{EXPERIMENTAL METHODOLOGY Obtaining healthy substrates}

During this study, seeds of a local variety of cowpea (Vigna unguiculata L. Walp) obtained from producers in Niamey were used as a laying substrate during the rearing of beetles. To obtain a healthy substrate, these seeds are kept in the freezer for a week in order to eliminate all stages of development of the beetles. These healthy substrates are used for the conduct of operations.

\section{Origin of strains of $\boldsymbol{B}$. atrolineatus}

Bruchidius atrolineatus strains come from cowpea seeds collected from producers in the Gaya region (Sahelo-Sudanian zone) in Niger. The study was conducted between December and February.

\section{Breeding of adults of $B$. atrolineatus}

A $1 \mathrm{~kg}$ sample of cowpea infested seeds is taken from producers. This sample is then brought back and stored in the laboratory in plexiglass parallelepiped boxes $(260 \times 130 \times 77 \mathrm{~cm})$ until the emergence of adults who have been used for breeding.

The seeds are sieved as soon as the insects emerge and the adults of Bruchidius atrolineatus obtained are introduced into a jar containing about 100 to $150 \mathrm{~g}$ of healthy cowpea seeds of the local variety.

Forty-eight hours later, the insects are removed and the contaminated seeds are left to incubate until the adults emerge. Upon emergence, the contents of the box are sieved to remove adults. Twenty four hours (24 hours) later, the contents of the sifted box the previous day are sifted again to obtain adults at most 24 hours old. These adults are used to determine the biological parameters of the first generation of $B$. atrolineatus.

\section{CONDUCT OF THE EXPERIMENT \\ Study of biological parameters}

To study the biological parameters of the first generation (lifespan, fertility, etc.) with the exception of the duration of hatching, the methodology consists in introducing a pair of $C$. maculatus into a petri dish containing 10 healthy seeds. The experiment is repeated twenty times. On the 10th day after laying (days on which all fertile eggs are hatched), fertile eggs and sterile eggs are counted. The sterile egg is distinguished from the fertile egg by its translucent appearance on a seed. Then the seeds are kept in their boxes until the adults emerge. At emergence, adult emergence monitoring is carried out and male and female individuals are counted in each box. The same procedure was carried out to determine the biological parameters of the second generation. To determine the duration of hatching of the experiment or duration of embryonic development, hatching monitoring is carried out. First, newly emerged adults of $B$. atrolineatus are placed in a breeding box containing about 150-200 healthy seeds. 24 hours after the insects are removed and the seeds bearing a single egg are chosen. The experiment consists in leaving a seed bearing a single egg in a petri dish. A total of 50 distributions havent been made. Each day the 50 seeds are observed and the hatched eggs are noted. The hatched egg is distinguished by a black spot inside it on a seed. Hatch monitoring lasts 10 days and unhatched eggs are considered sterile.

\section{Parameters studied}

Following the previous experiments, the following parameters are determined:

- The lifespan of the adult: It is the time interval between the emergence of the insect and its death;

- The number of eggs laid per female $(\mathrm{N})$ which corresponds to the total number of eggs laid per female during its lifetime.

- Fertility rate: This is the percentage of fertile eggs out of the total number of eggs laid;

- The larval survival rate (S): It is the percentage of individuals emerged relative to the total number of fertile eggs;

- The emergence rate (TE): it is the percentage of individuals emerged compared to the total number of eggs laid;

- The duration of embryonic development or duration of hatching: this is the time between the emission of an egg on a seed and the moment when it enters the seed;

- The duration of development (T): this is the time between the emission of an egg on a seed and the emergence of the adult;

- The sex ratio $(\mathrm{R})$ corresponds to the numerical ratio between males and females of the offspring.

\section{STATISTICAL DATA ANALYSIS}

For data analysis, the STAT VIEW software. rar. Version 1999 was used for the calculation of means (Anova). The differences in means between the different generations taken two by two are compared by the smallest significant difference at the 5\% threshold (Fischer test). The figures were generated using Excel software.

\section{RESULTS}

\section{Lifespan of Bruchidius atrolineatus}

Variation in lifespan of $B$. atrolineatus according to generations

Examination of the results in Table 1 shows that the lifespan of Bruchidius atrolineatus varies between generations. Indeed, statistical analysis shows that adults 
of the second generation live longer than those of the first generation. The longevity of Bruchidius atrolineatus is $9.75 \pm 2.933$ days for the second generation while that of the first generation is $8.2 \pm 1.072$ days.

Table-1: Variation in the average lifespan of $B$. atrolineatus according to generations

\begin{tabular}{|l|l|l|l|}
\hline Generations & Average life (days) & Female lifespan (days) & Male lifespan (days) \\
\hline Gaya G1 & $8,2 \pm 1,072 \mathrm{a}$ & $7,3 \pm 1,20 \mathrm{a}$ & $9,1 \pm 1,918 \mathrm{a}$ \\
\hline Gaya G2 & $9,75 \pm 2,933 \mathrm{~b}$ & $9,8 \pm 2,23 \mathrm{~b}$ & $9,6 \pm 3,55 \mathrm{a}$ \\
\hline
\end{tabular}

N.B: In the same column, the means followed by the same letter are not significantly different at the 5\% threshold (Newman and Keuls test)

Taking gender into account, statistical analysis reveals that the lifespan of males is the same regardless of generation. On the other hand the lifespan of the females varies according to the generations. Second generation females live longé $(9.8 \pm 2.23$ days $)$ than first generation females $(7.3 \pm 1.20)$.

Fertility of Bruchidius atrolineatus by generation Variation in the average number of eggs laid according to generations

The results in Table 2 show that the fertility of Bruchidius atrolineatus varies between generations.
Indeed, the statistical analysis shows a significant difference in the average number of eggs laid according to the generations. The number of eggs laid is higher in the second generation which records an average of 65.7 \pm 18.25 eggs per female and lower in the first generation with an average of $59.25 \pm 16.39$ eggs per female.

On the other hand, the fertility rate of eggs does not seem to vary according to generation. Indeed, whatever the generation considered, the fertility rate is almost $90 \%$.

Table-2: Fertility rate according to generation

\begin{tabular}{|c|c|c|c|}
\hline Generations & $\begin{array}{c}\text { Average number of } \\
\text { eggs laid }\end{array}$ & $\begin{array}{c}\text { Average number of } \\
\text { fertile eggs }\end{array}$ & Fertility rate (\%) \\
\hline Gaya G1 & $59,25 \pm 16,39 \mathrm{a}$ & $55,65 \pm 22,32 \mathrm{a}$ & 93,92 \\
\hline Gaya G2 & $65,7 \pm 18,25 \mathrm{~b}$ & $58,83 \pm 15,53 \mathrm{a}$ & 89,54 \\
\hline
\end{tabular}

N.B: In the same column, the means followed by the same letter are not significantly different at the 5\% threshold (Newman and Keuls test)

Evolution of the daily fertility of $B$. atrolineatus according to the generations

Examination of Table 3 shows that, in Bruchidius atrolineatus, the laying activity begins on the first day of the infestation. These results show that, regardless of the generation considered, most of the eggs are laid during the first four days of the infestation. Thus, $88.93 \%$ of eggs for G1 and $82.93 \%$ of eggs for G2 are laid during the first four days of the female's life.

Table-3: Cumulative percentage of eggs laid during the female's life

\begin{tabular}{|c|c|c|c|c|c|}
\hline Generations & \% 1st day & \% the first two days & \% the first three days & \% the first four days & Leftover eggs \\
\hline Gaya G1 & 45,99 & 68,18 & 80,86 & 88,93 & 11,07 \\
\hline Gaya G2 & 26,02 & 45,88 & 65,89 & 82,93 & 17,07 \\
\hline
\end{tabular}

Variation in larval survival rates and emergence rates

Table 4 shows the larval survival rate and the emergence rate according to the generations. Analysis of these results shows that the larval survival rate remains low regardless of the generation considered. Consequently, the larval mortality rate is high, where almost $80 \%$ of the larvae that have entered have not given birth to adults. This also results in a low emergence rate where more than $81 \%$ of the larvae penetrated did not give adults. These results confirm that the emergence of adults is strongly linked to the development capacity of the larvae which have returned to the seeds.

Table-4: Average number of eggs laid, Average number of fertile eggs, Average number of emergent adults, Larval survival rate (S) and Emergence rate (T.E)

\begin{tabular}{|c|c|c|c|c|c|}
\hline Generations & $\begin{array}{c}\text { Average number of } \\
\text { eggs laid }\end{array}$ & $\begin{array}{c}\text { Average number of } \\
\text { fertile eggs }\end{array}$ & $\begin{array}{c}\text { Average number of } \\
\text { adults emerged }\end{array}$ & $\begin{array}{c}\text { Larval survival } \\
\text { rate (S) }(\boldsymbol{\%})\end{array}$ & $\begin{array}{c}\text { T.E } \\
(\%)\end{array}$ \\
\hline Gaya G1 & $59,25 \pm 16,39 \mathrm{a}$ & $55,65 \pm 22,32 \mathrm{a}$ & $11,10 \pm 0,29 \mathrm{a}$ & 19,94 & 18,75 \\
\hline Gaya G2 & $65,7 \pm 18,25 \mathrm{~b}$ & $58,83 \pm 15,53 \mathrm{a}$ & $11,9 \pm 9,27 \mathrm{a}$ & 20,22 & 18,11 \\
\hline
\end{tabular}

N.B: In the same column, the means followed by the same letter are not significantly different at the 5\% threshold (Newman and Keuls test) 


\section{Variation in sex ratio according to generations}

The results in Table 5 show that the sex ratio varies across generations. It is determined by relating the average number of males emerged to the total number of individuals emerged. In this case if the percentage of the ratio is greater than $50 \%$, the sex is in favor of the males otherwise it is in favor of the females. Our observations indicate that the sex ratio is neither in favor of males $(50 \%)$ nor in favor of females $(50 \%)$ for the first generation. On the other hand, for the second generation, the sex ratio is in favor of males (more than $50 \%$ ).

Table-5: Average total number of emerged adults, average number of emerged adults by sex and sex ratio (R)

\begin{tabular}{|c|c|c|c|c|}
\hline Generations & Emerged adults & Emerged females & Emerged males & Sex-ratio (R) \\
\hline Gaya G1 & $11,10 \pm 0,29 \mathrm{a}$ & $5,5 \pm 1,75 \mathrm{a}$ & $5,6 \pm 0,25 \mathrm{a}$ & $50 \%$ \\
\hline Gaya G2 & $11,9 \pm 9,27 \mathrm{a}$ & $5,52 \pm 2,7 \mathrm{a}$ & $6,38 \pm 3,8 \mathrm{~b}$ & $53,61 \%$ \\
\hline
\end{tabular}

N.B: In the same column, the means followed by the same letter are not significantly different at the 5\% threshold (Newman and Keuls test)

Variation in the duration of development of Bruchidius atrolineatus according to generations

The duration of embryonic development of Bruchidius atrolineatus does not seem to vary according to the generation (Table 6). Indeed the statistical analysis reveals that the duration of embryonic development is the same whatever the generation. This duration is around four days.

On the other hand, the overall development time varies according to the generations. Statistical analysis indicates that second-generation insects have a much longer development time $(42.08 \pm 2.73$ days $)$ than the first generation $(37.09 \pm 3.60$ days $)$.

This results in a variation in the duration of post-embryonic development which is the difference between the duration of total development and the duration of embryonic development. In fact, second generation insects have a longer post-embryonic development period (37.28 days) than that of the first generation (32.5 days).

Table-6: Duration of development (T), Duration of post-embryonic development (DDPE), Duration of embryonic development (DDE) of $B$. atrolineatus according to generation

\begin{tabular}{|c|c|c|c|}
\hline Generations & DDE (days) & DDPE(days) & T (days) \\
\hline Gaya G1 & $4,59 \pm 1,06 \mathrm{a}$ & 32,5 & $37,09 \pm 3,60 \mathrm{a}$ \\
\hline Gaya G2 & $4,8 \pm 0,88 \mathrm{a}$ & 37,28 & $42,08 \pm 2,73 \mathrm{~b}$ \\
\hline
\end{tabular}

N.B: In the same column, the means followed by the same letter are not significantly different at the 5\% threshold (Newman and Keuls test)

\section{DISCUSSION}

The results obtained on the various parameters studied show a certain variability between generations. The analysis of longevity according to generations for the Gaya strain (Sahelo-Sudanian zone) shows that adults of the second generation live longer than those of the first generation.

These results corroborate with those found by Alfari [9] in the control during the same period and under the same conditions in Niamey. This author found an average lifespan of $8.80+2.44$ days for the Balleyara strain in the control. But adults give a different answer when they are fed sucrose water. Under these conditions, Doumma [10] and Alfari [9] found a lifespan of 30 days and $35.30+15.69$ days respectively. While the longevity of Callosobruchus maculatus hardly exceeds 6 days [6, 11] under the same climatic conditions in Niger, it is the sympatric species of Bruchidius atrolineatus in storage.

The difference in longevity observed between generations may be due to the thermo and photoperiodic changes between December and February. Analyzing the mortality factors in B. atrolineatus at different stages of development in a Sahelian agrosystem, Alzouma [2] showed that the differences in mortality observed between pure cowpea cultures and associated cultures (milniébé) were due to the difference in microclimate prevailing in each of these crops.

The fertility analysis shows that the fertility at this period of December and February is low whatever the generation. In fact, the average number of eggs laid in the second generation $(65.7 \pm 18.25)$ is much higher than that in the first generation $(59.25 \pm 16.39)$. But with a larval survival rate ( $19.94 \%$ for G1 and $20.22 \%$ for G2) and an emergence rate (18.75\% for G1 and $18.11 \%$ ) for $\mathrm{G} 2)$ very low for both generations.

These low larval survival and emergence rates make it possible to affirm that, under our study conditions, the emergence of this insect is strongly linked to the development capacity of the larvae having penetrated into the seeds. The low fertility can be explained by the appearance of diapauses on certain insects during this period. The work of Desroches and Huignard [12] on B. atrolineatus reveals that when the larval mortality rate increases, the emergence rate decreases. The fertility of $B$. atrolineatus varies depending on the geographical origin of the strain but 
also on the period of study. By studying the biological parameters of $B$. atrolineatus according to the varieties, Moumouni [6] found an average fecundity of $65.05 \pm$ 25.07 eggs for the Niamey strain. Under the same experimental conditions, Alfari [9] found in the control a fertility of $41.50+8.58$ eggs for the strain of Balleyara. In any case this study was conducted between December and February periods of low temperatures in Niger. During this period, adults become more and more diapositive both in the Sahelian zone and in the Guinean zone $[13,14]$. several authors state that reproductive diapause is induced during development in $B$. atrolineatus and depends on the thermo and photoperiodic conditions under which it takes place [15, $16,14]$. It is all the more intense and more difficult to lift when it is induced by low temperatures [14]. In various tropical insects such as the Diptera Sarcophagi [17, 18], the Leptidoptera Noctuidae $[19,20]$ or in the hymenoptera Cynipidae (Leptopidina boulardi) [21] Experimental laboratory studies have shown that the drop in rearing temperature induces diapause (which takes place at the nymphal stage) in these insects. The work of Germain et al. [22] revealed that more than $50 \%$ of adults of $B$. atrolineatus in mid-December and see $100 \%$ in January and February are in diapause. Compare to our results, these changes in spawning behavior by this insect, can be explained by the climatic changes observed in recent years.

Analysis of the sex ratio (percentage of males in relation to the total number of adults emerged) shows that this ratio is neither in favor of males nor in favor of females for the first generation $(50 \%)$. This trend has already been observed by Doumma [10] and Moumouni [6] in Niamey under the same experimental conditions. By cons sex is in favor of males for the second generation. But the sympatric species (Callosobruchus maculatus) $[23,11]$ gives a different response to West Niger. Thus, according to these authors, the sex ratio of C. maculatus is in favor of females in Niamey.

The results on the duration of development show that the duration of embryonic development does not vary between generations. Our results reveal that the duration of embryonic development hardly exceeds 5 days. These results corroborated with those found by Moumouni [6] on B. atrolineatus (4.6 days) and Doumma [11] on C. maculatus (4.35 days). On the other hand, the overall development time varies according to the generations. Second generation adults have a longer development time $(42.08 \pm 2.73)$ than first generation adults $(37.09 \pm 3.60)$. This results in an increase in the duration of post-embryonic development for the second generation. These results are close to those found by Alfari [9] on the Balleyara strain in the control for the first generation during the same period in Niamey. According to this author, the development period of this insect is $39.24+0.71$ days and remains the same whether it is nourished by flowers of certain trees such as
Balanites aegyptiaca, Neocarya macrophylla, Acacia seyal and Bauhinia rufescens or with sucrose water.

The evolution of mortality according to generations shows that insect mortality occurs on the fifth day of the operation for both generations. And this mortality is much more spread out over time for the second generation than for the first generation. Thus the insects of the first generation do not exceed J13 while those of the second generation can survive until J19. These results have already been demonstrated by Alfari [9] for the Balleyara strain under the same experimental conditions. According to this author, mortality for this strain occurs on the fifth day (D5) of the infestation. But insects give a different response when fed by sucrose water or floral nectars from certain wild trees. Thus by using saccharosed water, Doumma [10], observes that the mortality in these insects begins in D11 and under the same experimental conditions, insects surviving in D59 were observed [9, 24].

\section{REFERENCES}

1. Baños R, Reca J, Martínez J, Gil C and Márquez AL. Resilience indexes for water distribution network design: a performance analysis under demand uncertainty. Water resources management. 2011; 25(10): 2351-2366.

2. Alzouma I. Reproduction and development of $B$. atrolineatus Pic at the expense of cultures of $V$. unguiculata L. Walp (Leguminosae: Papilionacae) in a Sahelian agro-system in Niger. Doctoral thesis, Université F. Rabelais de Tours. 1987:162.

3. Ayres MP and Lombardero MJ. Assessing the consequences of global change for forest disturbance from herbivores and pathogens. The Science of the Total Environment. 2000; 262: 263-286.

4. Lale NES and Vidal S. Effect of constant temperature and humidity on oviposition and development of Callosobruchus maculatus (F.) and Callosobruchus subinnotatus (Pic) on bambara groundnut, Vigna subterranea (L.) Verdcourt. J. Stored Prod. Res. 2003;39 : 459-470.

5. Nyamador SW. Influence of treatments based on essential oils on the reproductive capacities of Callosobruchus subinnotatus Pic. And Callosobruchus maculatus F. (Coleoptera: Bruchidæ): 152 Mechanism of action of the essential oil of Cymbopogon giganteus Chiov. Doctoral thesis, University of Lomé. 2009: 197

6. Moumouni DA. Mapping of the biological parameters of Callosobruchus maculatus Fab. (Coleoptera-Bruchidae), cowpea pest (Vigna unguiculata L. Walp) in Niger, Master II dissertation, Abdou Moumouni University / Niger.2011:56.

7. Doumma A and Alzouma I. Effects of Boscia senegalensis (Pers.) Lam. Ex Poir. (Capparaceae) on the evolution of beetle populations in traditional 
cowpea (Vigna unguiculata L. Walp) storage systems in the Sahelian zone. Tropicultura. 2001: 19(4): 199-202.

8. Sanon KB, Bâ AM, Dexheimer J. Mycorrhizal status of some fungi fruiting beneath indigenous trees in Burkina Faso. Forest ecology and management. 1997 Oct 22;98(1):61-9.

9. Alfari BY. Influence of the flower-based diet of four plant species on the biological parameters of Callosobruchus maculatus Fab. and Bruchidius atrolineatus Pic. (Coleaptera: Bruchinea), cowpea pests (Vigna unguiculata Walp.). Master II dissertation, Faculty of Agronomy-Niamey. 2012:69.

10. Doumma A. Contribution to the research of methods of control against Bruchudius atrolineatus Pic. And Callosobruchus maculatus Fab. (Coleoptera: Bruchidæ), Cowpea pest (V. unguiculata L. Walp) in the Sahelian zone. Doctoral thesis. Univ. Abdou Moumouni from Niamey. 1998:135.

11. Doumma A.. Influence of two control alternatives on the reproductive capacities of Callosobruchus maculatus Fab. (Coleoptera-Bruchidae), cowpea pest (Vigna unguiculata Walp.): Thesis of State Doctorate. United. Abdou Moumouni de Niamey. 2012:171.

12. Desroches $P$ and Huignard J. Effect of larval density on development and induction of reproductive diapause in Bruchidius atrolineatus. Entomol. Exp. Appl. 1991; 61: 255-263.

13. Germain JF, Monge JP, Huignard J. Development of two bruchid populations (Bruchidius atrolineatus (Pic) and Callosobruchus maculatus (Fab.)) infesting stored cowpea (Vigna unguiculata Walp) pods in Niger. Journal of Stored Products Research. 1987 Jul 1;23(3):157-62.

14. Glitho IA. The Bruchidae pests of Vigna unguiculata Walp. In the Guinean zone. Analysis of reproductive diapause in males of Bruchidus atreolineatus Pic. Doctoral thesis, Univ. F. Rabelais, Tours. $1990: 100$.
15. Lenga A. The reproductive diapause in Bruchidius atrolineatus Pic. Physiological and evolutionary consequences - Analysis of the variability of responses to factors inducing diapause. Doctoral thesis in Science. United. F. Rabelais Tours.1991 : 109.

16. Lenga A, Monge JP, Huignard J. Role of thermal factors in reproductive diapause induction in Bruchidius atrolineatus Pic (Coleoptera, Bruchidae). Colloques de l'INRA (France). 1990.

17. Denlinger DL. Diapause potential in tropical flesh flies. Nature. 1974; 256: 223-224.

18. Denlinger DL. Pupal diapause in tropical flesh flies: environmental and endocrine regulation, metabolic rate and genetic selection. The Biological Bulletin. 1979 Feb;156(1):31-46.

19. Jacquemard $P$. The reproductive diapause of Bruchidius atrolineatus. Protein changes in the hemolymph from some responses to artificial selection. D.E.A Univ. Tours.1976:56.

20. Hackett DS, Gatehouse AG. Diapause in Heliothis armigera (Hübner) and $\mathrm{H}$. fletcheri (Hardwick)(Lepidoptera: Noctuidae) in the Sudan Gezira. Bulletin of Entomological research. 1982 Sep;72(3):409-22.

21. Carton Y and Claret J. Adaptive significance on a temperature induced diapause in a cosmopolitan of Drosophila. School. Ent. 1982 ; 7: 3-12.

22. Germain JF, Huignard J, Monge JP. Influence of host plant inflorescences (Vigna unguiculata) on the emergence of the reproductive diapause of Bruchidius atrolineatus. Ent. Exp. Appl.1985; 39 : 35-42.

23. Conny Sc. The possibilities of biological control for the protection of cowpeas (Vigna unguiculata L. Walp) after harvest. Internship report. DFPV Niamey.1991:58.

24. Monge JP, Germain JF, Huignard J. Importance des variations thermiques sur l'induction de la diapause reproductrice chez Bruchidius atrolineatus Pic (Coléoptère Bruchidae). Acta oecologica. Oecologia applicata. 1988;9(3):297-307. 